\title{
Stability of clavulanic acid in PEG/citrate and liquid-liquid extraction in aqueous two-phase system
}

\author{
M.N. Carneiro-da-Cunha ${ }^{a}$, K.P.S. Souza ${ }^{a}$, A.M.O. Mota ${ }^{b}$, J.A. Teixeira $^{\mathrm{b}}$, C.S. Porto ${ }^{\mathrm{a}}$, \\ T.S. Porto ${ }^{\mathrm{a}, \mathrm{c}}$, A.L.F. Porto ${ }^{\mathrm{a}, *}$ \\ a Federal Rural University of Pernambuco (UFRPE), Dom Manuel de Medeiros, Dois Irmãos, 52171-900 Recife-PE, Brazil \\ ${ }^{\mathrm{b}}$ Institute for Biotechnology and Bioengineering, Centre of Biological Engineering, University of Minho, Campus Gualtar, 4710-057 Braga, Portugal

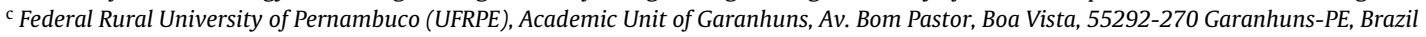

\section{A R T I C L E I N F O}

\section{Article history:}

Received 9 January 2014

Received in revised form 5 April 2014

Accepted 27 April 2014

Available online 6 May 2014

\section{Keywords:}

Clavulanic acid

ATPS

PEG

Citrate salts

Stability

\begin{abstract}
A B S T R A C T
$\beta$-Lactamases are enzymes responsible for the hydrolysis of $\beta$-lactam antibiotics, being produced by several pathogenic bacteria. Clavulanic acid is a commercially and clinically important $\beta$-lactamase inhibitor, its extraction being possible by the application of aqueous two-phase system. In this study, clavulanic acid stability was investigated at different molar mass PEG $\left(400,1000\right.$ and $\left.20000 \mathrm{~g} \mathrm{~mol}^{-1}\right)$ and at different citrate concentrations (5 and 20\%) PEG/citrate aqueous-two phase systems (ATPS), under different $\mathrm{pH}$ values (4.0-8.0). Clavulanic acid extraction was also evaluated. Low citrate concentration and PEG $20000\left(\mathrm{~g} \mathrm{~mol}^{-1}\right)$ ATPS, at pH 6.0, were shown to be the systems that presented the highest clavulanic acid stability. Based on this, a factorial design $2^{2}$ was used to evaluate CA extraction, being PEG $(20,25$ and $30 \%$ ) and citrate $(5,10$ and $15 \%)$ concentrations the parameters evaluated. Clavulanic acid was extracted into the PEG-rich phase $\left(133.66 \mathrm{mg} \mathrm{L}^{-1}\right)$, the highest values of the partition coefficient and yield being $K=5.92, Y=103.53 \%$, respectively The ATPS was not only effective on clavulanic acid extraction, but also its degradation was minimal. These results clearly indicate that ATPS can be successfully applied as a first step for the purification of clavulanic acid.
\end{abstract}

(c) 2014 Elsevier B.V. All rights reserved.

\section{Introduction}

The use of antibiotics to control infectious diseases is greatly hindered by bacterial resistance. One of the most important resistance mechanisms exhibited by a variety of Gram-positive and Gram-negative bacteria is their ability to produce $\beta$-lactamases, as $\beta$-lactamases hydrolyse the $\beta$-lactam ring inactivating penicillins and cephalosporins [1]. The discovery of clavulanic acid (CA) and its application as a $\beta$-lactamase inhibitor in the presence of antibiotics proved to be an effective approach to face antibiotic resistant bacteria [2].

CA is a mechanism-based inhibitor because it is recognized as a substrate by $\beta$-lactamase. CA binds covalently to the enzyme producing chemical modifications (rearrangements) that change the enzyme structure in an irreversible way [3]. CA is a potent antibiotic inhibitor of "serine" (or classes A, C, and D) $\beta$-lactamases. It is used in conjunction with amoxicillin in a salt (potassium clavulanate)

\footnotetext{
* Corresponding author. Tel.: +55 813320 6345; fax: +55 8133206057 .

E-mail address: analuporto@yahoo.com.br (A.L.F. Porto).
}

form and prescribed clinically as co-amoxiclav (Augmentin ${ }^{\mathrm{TM}}$ in USA, Clavulin $^{\mathrm{TM}}$ in Brazil) or with ticarcillin (Timentin ${ }^{\mathrm{TM}}$ ) [4].

The CA molecule is chemically unstable, due to the susceptibility of the carbonyl group linked to the beta-lactam ring, which can, in the presence of water, suffer an acidic (H+)- or alkaline $(\mathrm{OH}-)$-catalyzed attack. This property demands, the development of efficient and cost-effective separation and purification processes that allow for the obtention of CA with the required high quality standards of quality for market approval [5].

Among the several techniques available for the purification of CA, aqueous two-phase systems (ATPS) extraction and purification has been studied [5-7]. Aqueous two-phase systems are formed when two hydrophilic components are mixed with water and they are above a threshold concentration [8]. These solutes may be two polymers or a polymer and a salt. The ATPS are a convenient and appropriate method for the extraction of biological substances due to the high water content (between $70 \%$ and $90 \%$ ) in both phases. This provides a pleasant environment to work with biologically active compounds because it preserves its molecular stability [9].

The use of CA in the pharmaceutical industry is increasing, consequently studies addressing the effect of $\mathrm{pH}$, temperature, types of salts and their concentrations on CA stability are of particular 


\begin{tabular}{|c|c|}
\hline \multicolumn{2}{|c|}{ Nomenclature } \\
\hline ATPS & aqueous two phase system \\
\hline $\mathrm{CA}$ & clavulanic acid \\
\hline PEG & polyethylene glycol \\
\hline$k$ & degradation rate constants $\left(\mathrm{h}^{-1}\right)$ \\
\hline K & partition coefficient \\
\hline Y & yield (\%) \\
\hline$M B$ & mass balance $(\%)$ \\
\hline$C_{T}$ & $\begin{array}{l}\text { clavulanic acid concentrations at the top phase } \\
\left(\mathrm{mg} \mathrm{L}^{-1}\right)\end{array}$ \\
\hline$C_{B}$ & $\begin{array}{l}\text { clavulanic acid concentrations at the bottom phase } \\
\left(\mathrm{mg} \mathrm{L}^{-1}\right)\end{array}$ \\
\hline$C_{T} V_{T}$ & clavulanic acid mass in top phase (mg) \\
\hline$C_{B} V_{B}$ & clavulanic acid mass in bottom phase (mg) \\
\hline$C_{i} V_{i}$ & initial clavulanic acid mass ( $\mathrm{mg}$ ) \\
\hline$C_{\mathrm{PEG}}$ & PEG concentration \\
\hline$C_{\mathrm{CIT}}$ & citrate concentration \\
\hline
\end{tabular}

importance [10]. Several research-groups have conducted studies on the stability of the CA from various sources in aqueous solutions under different conditions. Generally, CA stability in aqueous solutions is better at $\mathrm{pH}$ between 6 and 7 and at temperatures in the range $20-30^{\circ} \mathrm{C}[5,7,11,12]$.

The main aim of this study was the evaluation of the stability of CA in PEG/citrate ATPS at different concentrations and $\mathrm{pH}$ values. In addition, the influence of system composition on CA was characterized.

\section{Materials and methods}

\subsection{Materials}

Potassium salt of CA used for all the solutions and the Imidazole used in CA determination were provided by Sigma-Aldrich (St. Louis, MO, USA) with 99\% purity. Ultra-pure polyethylene glycols (PEG) were purchased from Sigma-Aldrich (St. Louis, MO, USA). All the other reagents were of analytical grade.

\subsection{Clavulanic acid stability in PEG and citrate salt solutions}

To evaluate CA the effect of PEG molecular weight in CA stability, $25 \%(\mathrm{w} / \mathrm{v})$ solutions for the several molecular weight PEG considered $\left(400,10000\right.$ and $\left.20000 \mathrm{~g} \mathrm{~mol}^{-1}\right)$ were prepared in Mcllvaine buffer at different volumes for $\mathrm{pH}$ values at 4.0-8.0. CA stability in citrate salts was done by preparing solutions of citrate salts at 5 and $25 \%(\mathrm{w} / \mathrm{v})$ using different concentrations of sodium citrate and citric acid for $\mathrm{pH}$ values ranging from 4.0 to 8.0.

CA stability experiments were done by adding a concentrate CA stock solution ( $300 \mathrm{mg} \mathrm{L}^{-1}$ ), reaching an initial CA concentration of $30 \mathrm{mg} \mathrm{L}^{-1}$, to test tubes containing $50 \mathrm{~mL}$ of PEG solution or citrate salts solutions. The solutions were then homogenized and aliquots of the solutions were withdrawn during a $24 \mathrm{~h}$ period at time intervals of $15 \mathrm{~min}$ in the first hours, and then at three hours intervals. The concentration of non-degraded CA was determined. According to Bersanetti et al. [12], CA degradation in aqueous solutions follows a pseudo-first-order kinetics according to Eq. (1), where $k_{2}$ is the second order degradation rate constant and C is CA concentration. After integration (Eq. (2)), the degradation rate constant $\left(k_{2}\right)$, can be estimated by linear regression of the experimental data.

$\frac{-d C}{d t}=k_{2} C$
Table 1

Levels of independent variables in the $2^{2}$ factorial design for CA extraction in aqueous two-phase system (ATPS) PEG/citrate.

\begin{tabular}{llll}
\hline Variables & \multicolumn{3}{c}{ Levels } \\
\cline { 2 - 4 } & \multicolumn{1}{c}{0} & 0 & +1 \\
\hline PEG concentration (\%) & 20.0 & 25.0 & 30.0 \\
Citrate concentration (\%) & 5.0 & 10.0 & 15.0 \\
\hline
\end{tabular}

$-\ln \frac{C}{C_{0}}=k_{2} t$

\subsection{Clavulanic acid extraction in aqueous two-phase system (ATPS) PEG/citrate}

A concentrated citrate solution ( $40 \% \mathrm{w} / \mathrm{w}$ ) was prepared by mixing appropriate amounts of sodium citrate $\left(\mathrm{Na}_{3} \mathrm{C}_{6} \mathrm{H}_{6} \mathrm{O}_{7} \cdot 2 \mathrm{H}_{2} \mathrm{O}\right)$ and citric acid $\left(\mathrm{C}_{6} \mathrm{H}_{8} \mathrm{O}_{7}\right)$ at $\mathrm{pH}$ 6.0. The required amount of this solution was mixed with a PEG $20000 \mathrm{~g} \mathrm{~mol}^{-1}$ solution in $15 \mathrm{~mL}$ graduated tubes with conical tips to achieve the desired composition system. PEG 20000 concentrations and citrate salt in each system varied according to the factorial design $2^{2}$ shown in Table 1 . The systems $(10 \mathrm{~g})$ were loaded with $2 \mathrm{~g}$ of the CA stock solution with initial concentration of $500 \mathrm{mg} \mathrm{L}^{-1}$. After mixing for $1 \mathrm{~min}$ in a vortex, the mixture was allowed to settle for $60 \mathrm{~min}$ at $20^{\circ} \mathrm{C}$, for phase separation. The phase volumes were measured, and each phase was separately withdrawn using pipettes and used for determining the CA concentration in each phase. The response variables were the partition coefficient $(K)$ and yield $(Y)$ on top and bottom phases. After all experiments, statistical analyzes was conducted using Statistica 8.0 software (Statsoft, Inc., Tulsa-OK, USA) [13].

\subsection{Clavulanic acid assay}

Bird et al. [14] described the spectrophotometric assay by reaction with imidazole, selected in this study. According to this method, the CA concentration is determined by measuring the amount of [1-(8-hydroxy-6-oxo-4-azooct-2-enol)-imidazole] at $312 \mathrm{~nm}$. This product is released by the reaction between CA and imidazole. To determine the CA concentration, a calibration curve from standard stock solutions of potassium clavulanate was used.

\subsection{Calculation of partition coefficient $(K)$, yield $(Y)$ and mass balance $(M B)$}

The CA distribution between phases was expressed in terms of the partition coefficient $(K)$, calculated as follows:

$K=\frac{C_{T}}{C_{B}}$

where $C_{T}$ and $C_{B}$ are CA concentrations $(\mathrm{mg} / \mathrm{L})$ at the top and bottom phases, respectively.

To evaluate the efficiency of extraction of CA, the yield $(Y)$ for each phase was calculated according to:

$Y_{x}=\left(\frac{C_{x} V_{x}}{C_{i} V_{i}}\right) \times 100$ for $x=T$ or $B$

where $C_{x} V_{x}$ is the mass of CA ( $\mathrm{mg}$ ) in the top (T) and bottom (B) phase volume, respectively. The $C_{i} V_{i}$ is the initial mass of CA (mg).

The mass balance $(M B)$ for $C A$ is:

$M B=\left(\frac{C_{T} V_{T}+C_{B} V_{B}}{C_{i} V_{i}}\right) \times 100$

where $C_{T} V_{T}$ and $C_{B} V_{B}$ is the mass of $C A$ in top phase (T) end bottom phase $(B)$, respectively, and the $C_{i} V_{i}$ is the initial mass of CA (mg). 

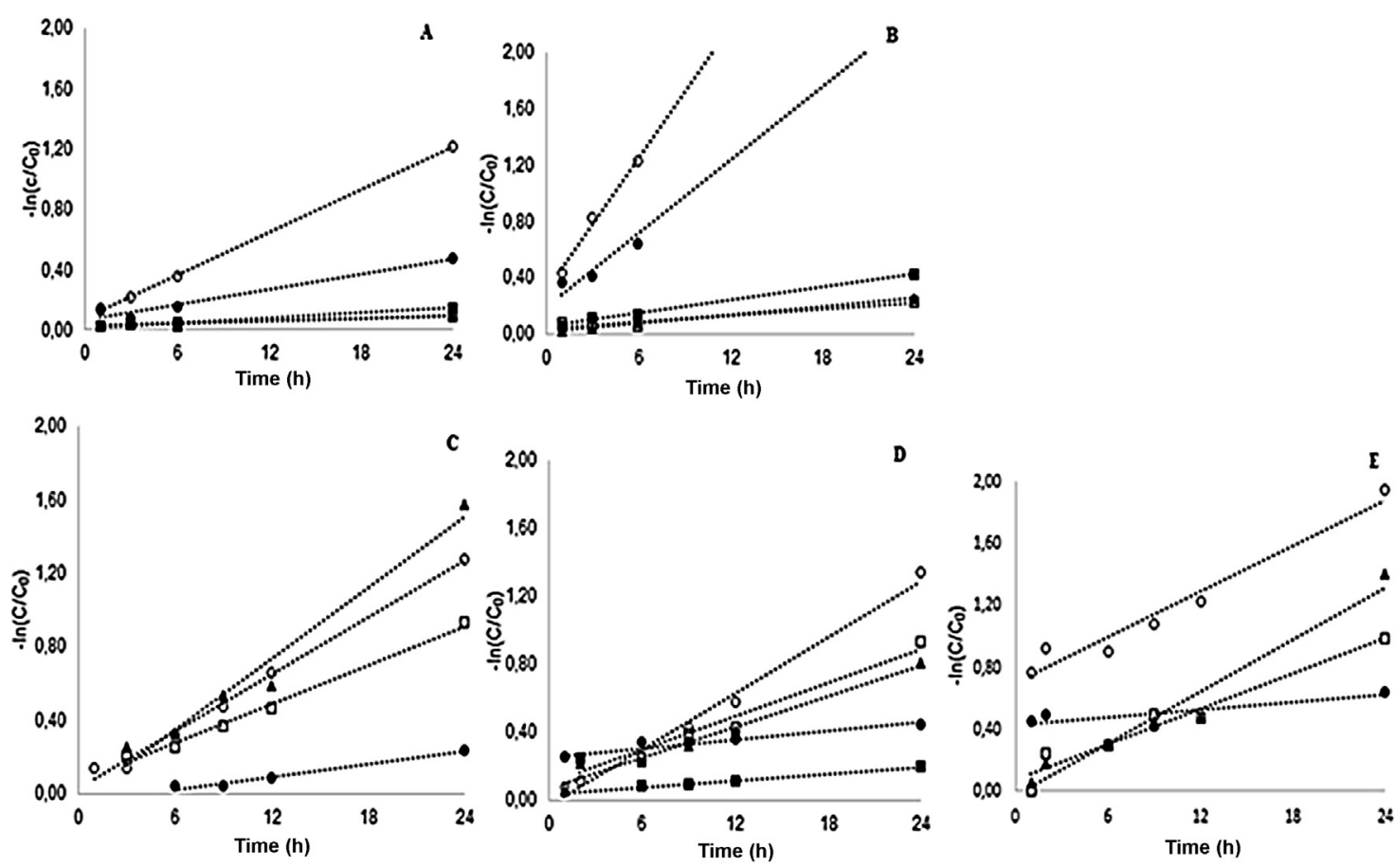

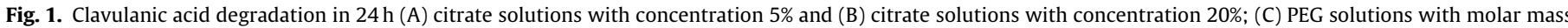

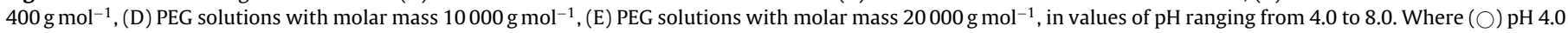
$(\bullet) \mathrm{pH}$ 5.0; ( $) \mathrm{pH} 6.0 ;(\square) \mathrm{pH} 7.0$ and $((\boldsymbol{\Delta}) \mathrm{pH}$ 8.0. Straight lines in the figures are the linear adjustment for each $\mathrm{pH}$.

\section{Results and discussion}

In Fig. 1 and in Table 2, the experimental results for CA stability in PEG and salts citrate are presented. The results show, as expected, that the CA degradation in aqueous solution follows a pseudo-first order kinetics (Eq. (1)). The CA degradation was similar to other beta-lactam compounds reported in the literature [15]. Straight lines in the figures correspond to the linear adjustments for to each $\mathrm{pH}$ value considered. The degradation rate constants $(k)$ presented in Table 2 were estimated by linear regression of the experimental results. From Fig. 1 and Table 2, it can be concluded that highest degradation rate constant was observed at PEG 20000 and $\mathrm{pH} 4$ while the lowest occurred at PEG 20000 and pH 6 after $24 \mathrm{~h}$.

\subsection{Clavulanic acid stability in sodium citrate}

Concerning the stability of CA under the studied salt concentrations the results showed an increase of $k$ with the increase of salt concentration (Table 2). This indicates that at high salt concentrations the CA is more susceptible to degradation.

The results from Table 2 showed that independently of the citrate concentration considered, the degradation in the first hour is residual when compared with the degradation in the following hours (up to $24 \mathrm{~h}$ ). The degradation rate constant, values after the $24 \mathrm{~h}$ are at least 8 times higher than in the first hour.

The influence of $\mathrm{pH}$ was different for the two salt concentrations studied (Table 2). At $5 \%$ of citrate, the increase of $\mathrm{pH}$ from 4 to 8 , led to a decrease in the CA degradation constant being the maximum and minimum values $0.0471 \mathrm{~h}^{-1}$ and $0.0029 \mathrm{~h}^{-1}$ On the other hand at $20 \%$ of citrate, the minimum constant rate obtained was $0.0074 \mathrm{~h}^{-1}$ at $\mathrm{pH}$ 7.0. Bersanetti et al. [12] evaluated the temperature and $\mathrm{pH}$ effect on the CA stability in phosphate buffer. The degradation constant values they reported at $20^{\circ} \mathrm{C}$ for $\mathrm{pH} 6.2$ and 7 are $0.0038 \mathrm{~h}^{-1}$ and $0.0067 \mathrm{~h}^{-1}$, respectively, which are in the range of values presented in this work. The lower values here reported for CA degradation at $\mathrm{pH} 7.0\left(0.0030 \mathrm{~h}^{-1}\right)$ may be related with the type of salt used.

Table 2

Degradation rate constant of clavulanic acid in the first hour (A) and from the first to 24th hour (B). (-) Not degraded clavulanic acid.

\begin{tabular}{|c|c|c|c|c|c|c|c|c|c|c|}
\hline \multirow[t]{2}{*}{$\mathrm{pH}$} & \multicolumn{2}{|c|}{$5 \%$ citrate salts } & \multicolumn{2}{|c|}{$20 \%$ citrate salts } & \multicolumn{2}{|c|}{ PEG $\quad 400\left(\mathrm{~g} \mathrm{~mol}^{-1}\right)$} & \multicolumn{2}{|c|}{ PEG $10000\left(\mathrm{~g} \mathrm{~mol}^{-1}\right)$} & \multicolumn{2}{|c|}{ PEG $\quad 20000\left(\mathrm{~g} \mathrm{~mol}^{-1}\right)$} \\
\hline & $K$ & $r^{2}$ & $K$ & $r^{2}$ & $K$ & $r^{2}$ & $K$ & $r^{2}$ & $k$ & $r^{2}$ \\
\hline \multicolumn{11}{|l|}{ (A) } \\
\hline 4 & 0.0018 & 0.9643 & 0.0032 & 0.8489 & 0.0027 & 0.8548 & 0.3437 & 0.9917 & 1.3023 & 0.9957 \\
\hline 5 & 0.0021 & 0.9190 & 0.0100 & 0.9370 & - & - & 0.0803 & 0.7472 & 0.8367 & 0.8658 \\
\hline 6 & - & - & 0.0006 & 0.9157 & - & - & - & - & - & - \\
\hline 7 & - & - & 0.0008 & 0.9122 & - & - & - & - & - & - \\
\hline 8 & - & - & - & - & - & - & - & - & - & \\
\hline \multicolumn{11}{|l|}{ (B) } \\
\hline 4 & 0.0471 & 0.9997 & 0.1561 & 0.9908 & 0.0517 & 0.9933 & 0.0552 & 0.9878 & 0.0495 & 0.9608 \\
\hline 5 & 0.0166 & 0.9547 & 0.0869 & 0.9940 & 0.0118 & 0.9785 & 0.0084 & 0.9311 & 0.0079 & 0.7014 \\
\hline 6 & 0.0054 & 0.9810 & 0.0156 & 0.9923 & - & - & 0.0066 & 0.9942 & - & - \\
\hline 7 & 0.0030 & 0.9210 & 0.0074 & 0.9082 & 0.0354 & 0.9888 & 0.0331 & 0.9515 & 0.0384 & 0.9449 \\
\hline 8 & 0.0029 & 0.8199 & 0.0101 & 0.9988 & 0.0645 & 0.9683 & 0.0301 & 0.9658 & 0.0561 & 0.9571 \\
\hline
\end{tabular}


After $24 \mathrm{~h}$ the CA concentration decreased more than $90 \%$ at lower $\mathrm{pH}$ values (4.0 and 5.0) for the highest citrate concentration tested, while at $5 \%$ of citrate the CA degradation was between 30 and $60 \%$. At $\mathrm{pH}$ above 6 and after $24 \mathrm{~h}$ the CA final concentration was always above $85 \%$ and $75 \%$, respectively for $5 \%$ and $20 \%$ of citrate.

Santos et al. [7] reported that at pH 6.0 the CA concentration decreased with the increase of ionic strength. They obtained a $10 \%$ decrease in CA at $3 \mathrm{M}$ ionic strength after $3 \mathrm{~h}$. In our case the CA concentration decrease at $\mathrm{pH} 6$ after $3 \mathrm{~h}$ was negligible for all citrate concentrations tested.

\subsection{Clavulanic acid stability in PEG}

The results for CA stability in Mcllvaine buffer ( $\mathrm{pH} 4.0$ at 8.0) with different molar mass of PEG $\left(400,10000\right.$ and $\left.20000 \mathrm{~g} \mathrm{~mol}^{-1}\right)$ at $25 \%$ concentrations, showed low values of CA degradation.

In the first hour, the highest degradation of CA occurred in PEG with molar mass $20000 \mathrm{~g} \mathrm{~mol}^{-1}$ at $\mathrm{pH} 4.0$ and 5.0 , being the constants rates 1.30 and $0.83 \mathrm{~h}^{-1}$, respectively. From Table 2, it is also possible to observe that for PEGs 10000 and 20000 at pH 4.0 the highest degradation values occurred in the first hour. The strong influence of $\mathrm{pH}$ on the $\mathrm{CA}$ degradation can be explained due to the nature of the carbonyl group which can be attacked by protons and hydroxide ions [15].

After $24 \mathrm{~h}$, results presented in Fig. 1 and Table 2 indicate that in the presence of PEG $10000 \mathrm{~g} \mathrm{~mol}^{-1}$, CA degradation remains small (Fig. 1D), with degradation rate constants varying between $0.05 \mathrm{~h}^{-1}$ at $0.03 \mathrm{~h}^{-1}$ for $\mathrm{pH} 4.0$ at 8.0 , respectively. However, the lowest CA degradation was observed using PEG with a molar mass of $20000 \mathrm{~g} \mathrm{~mol}^{-1}$ at pH 6 with a constant rate close to zero (Table 2). Pereira et al. [5] studied the stability of CA at pH 6.5 in PEG with different molar mass $\left(2000,4000\right.$ and $\left.6000 \mathrm{~g} \mathrm{~mol}^{-1}\right)$ at different concentrations ( 5 and $15 \mathrm{wt} \%$ ) during $3 \mathrm{~h}$ under $25^{\circ} \mathrm{C}$. These authors observed that the addition of different types and concentrations of PEG did not affect CA stability. They reported that, since PEG is relatively inert, these results were expected. The results obtained in this study indicate that at pH 6.0, CA was more stable for all PEGs molar mass tested, which is in accordance with Pereira et al. [5].

Our results suggest that the best condition for stabilization of CA molecule occurs at higher PEG molar mass (20000 $\left.\mathrm{g} \mathrm{mol}^{-1}\right)$ and pH 6.0.

The main aim of this work was to study the partition of CA in a PEG/citrate ATPS at minimum CA degradation conditions. Previous works reported the migration of CA to the PEG rich phase $[6,16,17]$. Consequently, the minimum CA degradation conditions are defined according to the minimum CA degradation conditions in the PEG rich phase.

Therefore the conditions used in the ATPS experiments are $\mathrm{pH}$ 6 and PEG $20000 \mathrm{~g} \mathrm{~mol}^{-1}$ as these are the conditions where the CA degradation is lower and good partition coefficients may be obtained. On the other hand, at the selected conditions the CA degradation in the salt-phase should be negligible or near zero considering the salt concentrations used in the partition experiments.

\subsection{Clavulanic acid partition in aqueous two phase systems PEG/citrate}

After establishing the best conditions for the stabilization of CA, its partition was characterized in ATPS. The influence of sodium citrate concentrations (5, 10 and 15\%) and PEG $20000 \mathrm{~g} \mathrm{~mol}^{-1}$ concentrations $(20,25$ and $30 \%)$ at $\mathrm{pH} 6.0$ was evaluated, using a $2^{2}$ factorial design. The obtained results are presented in Table 3.

The first run was the only one that did not form two phases probably because the concentration of the components of the system was below the system's critical point.

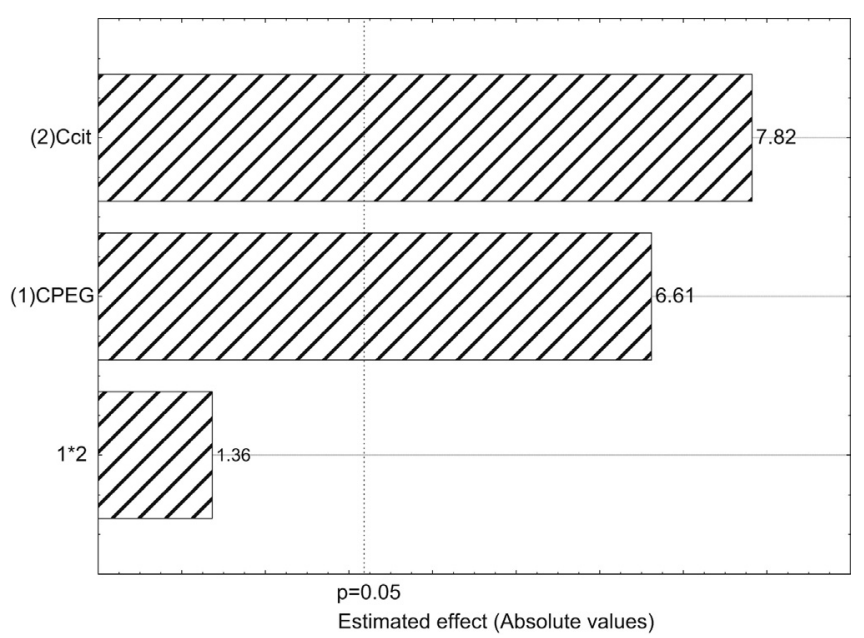

Fig. 2. Pareto chart of main effects, and the response variable partition coefficient of clavulanic acid.

The partition coefficients obtained had values above 1.0 $\left(1.26<K_{\mathrm{CA}}<5.92\right)$, indicating that the CA molecule has a greater affinity for the polymer phase. Some authors testing ATPS also observed CA migration for the PEG-rich phase, even with other salts than citrate $[5,16,18]$.

Similar values of the partition coefficients $(K=2.3-2.7)$ were reported by Videira and Aires-Barros [16] when studying the CA partition in ATPS with PEG molar mass ranging from 400 to 6000 $\left(\mathrm{g} \mathrm{mol}^{-1}\right)$ at $\mathrm{pH} 7$ and 8 . These authors also stated, as observed in our experiments, that there was no excluded volume effect on CA partition. The excluded volume effect occurs when there is no available volume in the PEG-rich phase due to the high molar mass and concentration of polymer that promotes the exclusion of the target molecule to the bottom phase decreasing the coefficient partition value [19]. The PEG used in this study has a high molar mass $\left(20000 \mathrm{~g} \mathrm{~mol}^{-1}\right)$, however, this phenomenon was not observed because of the small size of CA molecule. In addition, hydrophobic structures on CA molecule allow its interaction with the more hydrophobic PEG-rich phase [16].

Fig. 2 Fig. 3 shows that the independent variables (1) PEG Concentration $\left(C_{\mathrm{PEG}}\right)$ and $(2)$ citrate concentration $\left(C_{\mathrm{CIT}}\right)$, were significant at $95 \%$ confidence for both response variables: the partition coefficient and the CA yield. The independent variable that most

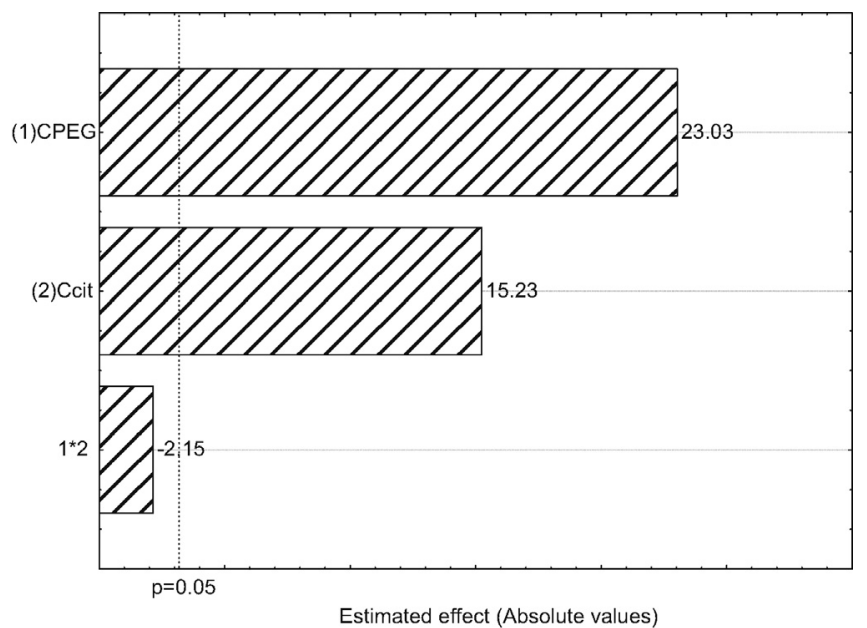

Fig. 3. Pareto chart of main effects and the response variable clavulanic acid yield in the PEG phase. 
Table 3

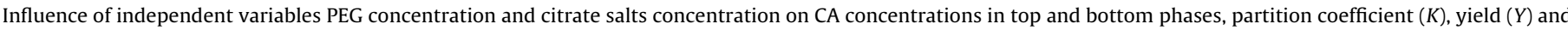
mass balance $(B M)$ according to the $2^{2}$ factorial designs.

\begin{tabular}{|c|c|c|c|c|c|c|c|c|c|c|}
\hline Run & $C_{\mathrm{PEG}}(\%)$ & $C_{\text {SALTS }}(\%)$ & $\begin{array}{l}\mathrm{CA}_{\mathrm{TOP}} \\
\left(\mathrm{mg} \mathrm{L}^{-1}\right)\end{array}$ & $\begin{array}{l}\text { СА воттом } \\
\left(\mathrm{mg} \mathrm{L}^{-1}\right)\end{array}$ & $\begin{array}{l}\text { VOL.TоP } \\
(\mathrm{mL})\end{array}$ & $\begin{array}{l}\text { VOL.воттом } \\
(\mathrm{mL})\end{array}$ & $(K)$ & $Y_{\mathrm{TOP}}(\%)$ & $\begin{array}{l}Y_{\text {воттом }} \\
(\%)\end{array}$ & $B M$ \\
\hline 1 & 20 & 5 & 0.00 & 0.00 & 0.0 & 0.0 & 0.00 & 0.00 & 0.00 & 0.00 \\
\hline 2 & 30 & 5 & 83.73 & 66.49 & 8.9 & 0.6 & 1.26 & 74.56 & 3.99 & 78.55 \\
\hline 3 & 20 & 15 & 105.05 & 67.82 & 4.9 & 4.1 & 1.55 & 51.48 & 27.81 & 79.28 \\
\hline 4 & 30 & 15 & 133.66 & 22.55 & 5.8 & 3.2 & 5.92 & 103.53 & 9.63 & 105.38 \\
\hline $5(C)$ & 25 & 10 & 125.00 & 63.83 & 6.8 & 2.7 & 1.96 & 85.00 & 17.23 & 102.23 \\
\hline $6(C)$ & 25 & 10 & 134.31 & 65.16 & 6.4 & 3.1 & 2.06 & 85.96 & 20.20 & 106.16 \\
\hline $7(C)$ & 25 & 10 & 134.31 & 54.52 & 6.4 & 3.0 & 2.46 & 85.96 & 16.36 & 102.31 \\
\hline $8(C)$ & 25 & 10 & 132.98 & 67.82 & 6.0 & 3.0 & 1.96 & 79.79 & 20.35 & 100.13 \\
\hline
\end{tabular}

positively influenced the CA partition was the $C_{\mathrm{CIT}}$ while the variable that most influenced the $C A$ yield was $C_{\mathrm{PEG}}$.

Our results suggest that higher $K$ values are obtained at higher sodium citrate and PEG concentrations. The conditions that favor CA partition for the top phase are 30\% (w/w) PEG concentration and $15 \%(w / w)$ concentration citrate. High PEG concentrations associated with high citrate concentrations favored partitioning for top phase and the partition coefficient increased (Table 2), which was also observed by Pereira et al. [5]. The increase of $K$ is related with the interactions between the CA properties, the high ionic strength of salt solution and the hydrophobic nature of PEG.

The highest value for CA yield (103.53\%), according to Fig. 4, was obtained in run 4 with $C_{\mathrm{PEG}} 30 \%(\mathrm{w} / \mathrm{w})$ and $15 \%(\mathrm{w} / \mathrm{w})$ citrate. The increase of the polymer and salt concentrations favored the accumulation of the target molecule in the PEG phase.

For these conditions, the volume of the top phase was much higher than the volume of the salt-rich phase. Having all these factor in mind and the high CA stability at this PEG molar mass and $\mathrm{pH}$ (see Section 3.2), its clear that is possible to obtained a good CA separation using PEG/citrate ATPS [5].

Furthermore, Silva et al. [18] reported that ATPS (PEG/phosphate) at low temperatures tends to increase the yield of CA in the PEG phase. These authors used a temperature of

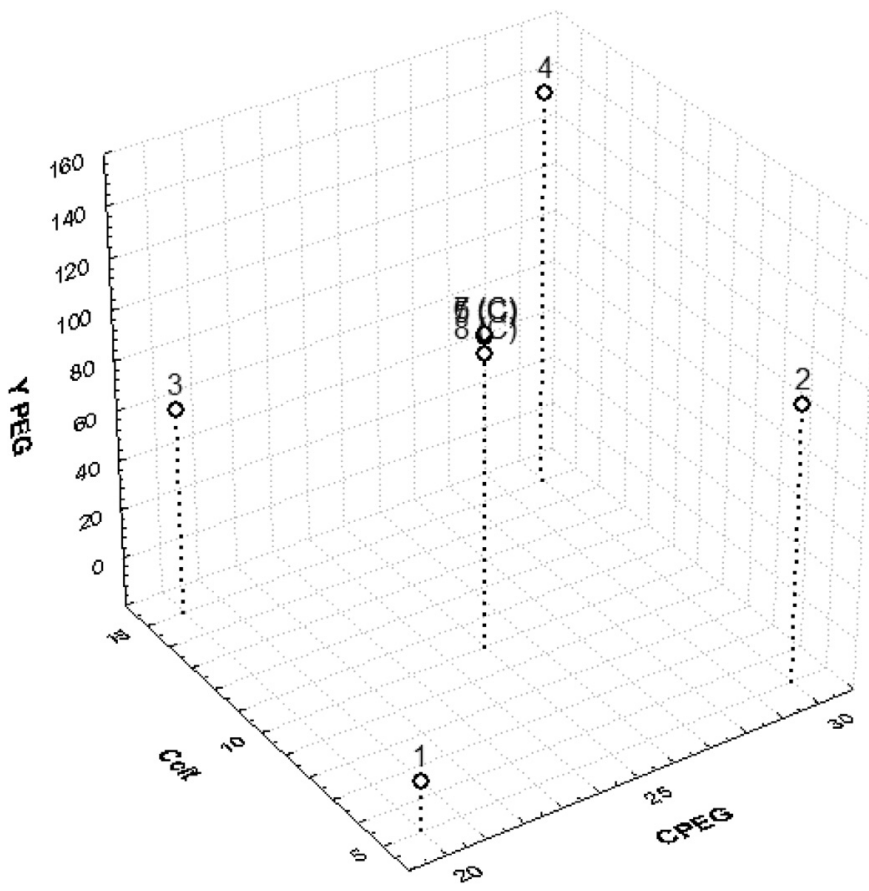

Fig. 4. Graphic representation of clavulanic acid yield in the PEG phase in relation to the concentration of citrate and PEG. $20^{\circ} \mathrm{C}$ and obtained about $100 \%$ yield, corroborating the temperature and the yield obtained in this work.

The best results reported by Hirata [17] for extraction of CA in an ATPS were obtained for a PEG $\left(400 \mathrm{~g} \mathrm{~mol}^{-1}\right)$ concentration of $21 \%(\mathrm{w} / \mathrm{w})$ and a phosphate concentration of $23.6 \%$ at $\mathrm{pH} 7.0$. Hirata reached $94 \%$ of CA yield and obtained the best PEG phase yield at their higher PEG and salt concentrations. Similar results were also obtained for other molecules such as rentamicin, where it is reported that an extraction yield of $91.3 \%$ was obtained for PEG/phosphate ATPS [20].

In the present work, the best yield obtained is higher than the ones reported in the literature for ATPS using PEG/salt $[16,18]$ and is similar to the results reported for aqueous two-phase polymer/polymer systems [5]. Comparing with the literature polymer/salt and polymer/polymer ATPS, a main advantage of the system presented in this work is the lower toxicity of the components used, especially the salt phase.

The partition and yield of CA into the PEG-rich phase can be due to the electrostatic repulsion effect of the sodium citrate. Sodium citrate in aqueous acid $\mathrm{pH}$ is decoupled, and negatively charged citric acid (anionic) and positively charged sodium ions (cationic) are formed. In acid conditions, the bottom phase system is rich in citric acid, therefore $C A$ is repelled from this phase because it has the same electric charge. Thus, CA migrates to the PEG-phase where, due to the PEG neutral charge, the repulsion is lower. In association with this phenomenon, the high molar mass PEG has a lower hydrophobicity that attracts less hydrophobic compounds. As CA is neither hydrophilic or hydrophobic [12], it is repulsed from saltphase due to its high ionic strength. It is reported that in PEG/salt ATPS if the PEG molar mass is increased the partition coefficient and the yield decreases $[16,18]$.

In our experiments, we observed a 5.92 partition coefficient and approximately $100 \%$ yield (Table 3 ), which is in the range of other works. Some works with PEG/phosphate reported a partition coefficient higher than 5.0, but the PEG molar mass used was smaller $[5,18]$. Our work suggested that PEG/citrate system is good for CA pre-purification, but it is still necessary to study the influence of PEG molar mass in order to evaluate if the partition coefficient can be improved without decreasing significantly the yield.

It is then possible to say that the CA migration to the PEG phase is related with the interaction of (1) the electrostatic repulsion effect of citrate, (2) the hydrophobic attraction character of PEG and (3) the neutral hydrophilic/hydrophobic properties of CA.

The analysis of the mass balances presented in Table 2, indicates that only in the runs 2 and 3 a degradation of CA was observed, showing that the CA partition in ATPS using PEG/citrate was effective. The mass balance values greater than $100 \%$ were considered within the margin of experimental error.

The results showed that a PEG/citrate ATPS with $30 \%(w / w)$ of PEG $\left(20000 \mathrm{~g} \mathrm{~mol}^{-1}\right)$ and $15 \%(\mathrm{w} / \mathrm{w})$ of citrate at $\mathrm{pH} 6.0$ is ideal for CA pre-purification. This system not only provides a high yield, but also low degradation rates are obtained. Moreover, citrate is a 
non-toxic salt with minimal environmental impact, which reinforces the usefulness of this ATPS, in the pre-purification of CA.

\section{Conclusions}

Low citrate concentration and PEG $20000\left(\mathrm{~g} \mathrm{~mol}^{-1}\right)$ ATPS, at $\mathrm{pH}$ 6.0, were shown to be the systems that presented the highest clavulanic acid stability. It was demonstrated that CA degradation follows a pseudo-first order kinetics.

The best results for CA concentration in the PEG/citrate ATPS were obtained at $\mathrm{pH} 6.0$ in a system containing 30\% of PEG and $15 \%$ of citrate. Under these conditions, the partition coefficient was 5.92 and the yield was $100 \%$ demonstrating the potential application of this non-toxic and environmental friendly ATPS in the pre-purification of CA.

\section{Acknowledgment}

The authors gratefully acknowledge the CAPES and CNPq (Process No. 150763/2013-1) for the financial support.

\section{References}

[1] G.L. Maranesi, A. Baptista-Neto, C.O. Hokka, A.C. Badino, World J. Microbiol. Biotechnol. 21 (2005) 509-514.
[2] K.H. Baggaley, A.G. Brownb, C.J. Schofield, Nat. Prod. Rep. 14 (1997) 309-333.

[3] F.J. Pérez-Llarena, G. Bou, Curr. Med. Chem. 16 (2009) 3740-3765.

4] D.A. Viana, M.N. Carneiro-Cunha, J.M. Araújo, B. Barros-Neto, J.L. Lima-Filho, A Converti, A. Pessoa-Jumior, A.L.F. Porto, Appl. Biochem. Biotechnol. 160 (2010) 1797-1807.

[5] J.F.B. Pereira, V.C. Santos, H.-O. Johansson, J.a.C. Teixeira, A. Pessoa, Sep. Purif. Technol. 98 (2012) 441-450.

[6] C.S. Silva, M.F. Cuel, V.O. Barreto, W.H. Kwong, C.O. Hokka, M. Barboza, N. Biotechnol. 29 (2011) 428-431.

[7] V.C. Santos, J.F.B. Pereira, R.B. Haga, C.O. Rangel-Yagui, J.A.C. Teixeira, A. Converti, Biochem. Eng. J. 45 (2009) 89-93.

[8] M. Perumalsamy, T. Murugesan, Braz. J. Chem. 26 (2009) 171-180.

[9] J.F. Ferreira, G.D.S. Padilha, E.B. Tambourgi, Exacta 7 (2009) 49-56.

[10] P.S. Saudagar, S.A. Survase, R.S. Singhal, Biotechnol. Adv. 26 (2008) 335-351.

[11] J. Haginaka, T. Nakagawa, T. Uno, Chem. Pharm. Bull. 29 (1981) 3334-3341.

[12] P.A. Bersanetti, R.M.R.G. Almeida, M. Barboza, M.L.G.C. Araújo, C.O. Hokka, Biochem. Eng. J. 23 (2005) 31-36.

[13] I. Statsoft, Statistica, version 8.0., 2008

[14] A.E. Bird, J.M. Bellis, B.C. Gasson, Analyst 107 (1982) 1241-1245

[15] J. Konecny, E. Felber, J. Gruner, J. Antibiot. 24 (1972) 135-141.

[16] M. Videira, M. Aires-Barros, J. Chromatogr. A 668 (1994) 237-240.

[17] D.B. Hirata, J.H.H.L. Oliveira, K.V. Leão, M.I. Rodrigues, A.G. Ferreira, M. Giulietti, M. Barboza, C.O. Hokka, Sep. Purif. Technol. 66 (2009) 598-605.

[18] C.S. Silva, E. Bovarotti, M.I. Rodrigues, C.O. Hokka, M. Barboza, Bioprocess Biosyst. Eng. 32 (2009) 625-632.

[19] A. Pessoa-Júnior, B.V. Kilikian, Manole - SP, 1st ed., 2005, p. 144.

[20] E. Esmanhoto, B.V. Kilikian, J. Chromatogr. B Analyt. Technol. Biomed. Life Sci. 807 (2004) 139-143. 